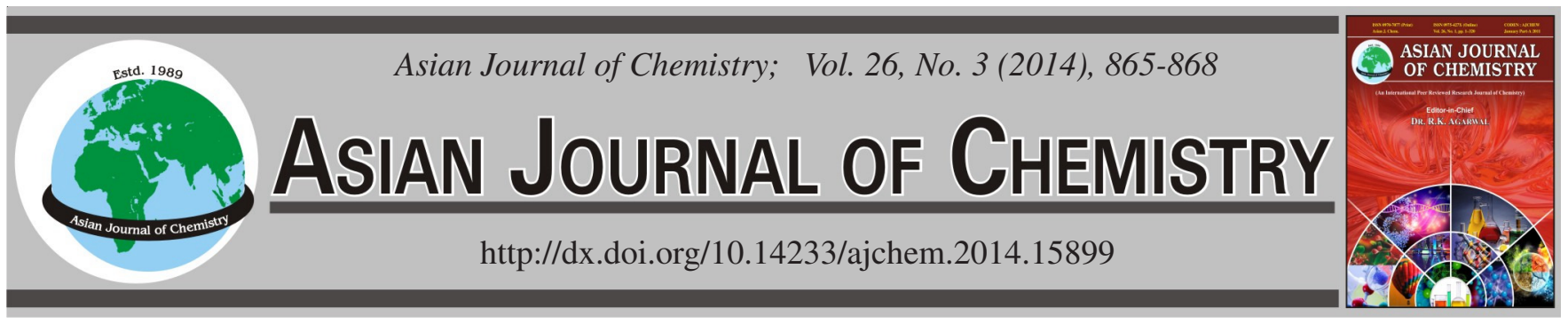

\title{
Common and Variation Peak Ratio Dual-Index Sequence Analysis of Vanillin-Sulfuric Acid Developing UV Fingerprint of Panax notoginseng
}

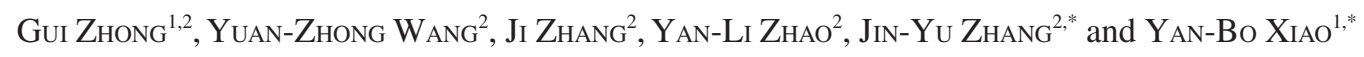

${ }^{1}$ Institute of Plant Nutrition and Fertilizer, Yunnan University of Nationalities, Kunming 650500, P.R. China

${ }^{2}$ Institute of Medicinal Plants, Yunnan Academy of Agricultural Sciences, Kunming 650200, P.R. China

*Corresponding author: Tel: +86 087165033564; E-mail: jyzhang2008@126.com; ybxiao@21.cn.com

\begin{abstract}
The vanillin-sulphuric acid developing-UV fingerprint of Panax notoginseng extracted by chloroform, ethanol and water was analyzed by common and variation peak ratio dual index sequence analysis. The results indicated that there was same effective quality evaluation for P. notoginseng extractions of chloroform, ethanol and water. The common peak ratios of the different seed sources and same producing areas of $P$. notoginseng ranged from 45 to $85 \%$, the variation peak ratios ranged from 9.38 to $61.90 \%$. There were relationships between results of experiment and information of samples. This method evaluated quality of $P$. notoginseng from different seed sources and same producing areas, which provided reference for quality evaluation of Chinese herbal medicine.
\end{abstract}

Keywords: Panax notoginseng, Vanillin-sulphuric acid, UV fingerprint, Traditional Chinese medicine.

ᄂ - - - - - - - - - - - - - - - - - - - - - - - - - - -

\section{INTRODUCTION}

Chemical fingerprint is an essential tool for the characterization of the sources of variance in plant materials ${ }^{1}$. Fingerprint techniques are utilized to gain a broader insight into chemical composition of medicinal plants and further to distinguish the origin of medicinal plants and classify their species ${ }^{2}$. Techniques like HPLC, NMR, UV and IR are commonly applied $^{3-5}$. More specifically, UV fingerprint (UV FP) is fast and need no complex pretreatment. It has already been used to discriminate the content of biodiesel feedstock and reflected the whole component information present in the biodiesel feedstock ${ }^{6}$. Yuan et al. ${ }^{7}$ applied the dual-index sequence analytical method to evaluate UV FP of Gentiana rigescens and clarified the similarity level among different areas.

Panax notoginseng (Burkill) F. H Chen (Araliaceae) as an important traditional Chinese medicine (TCM) has been cultivated in China for more than 400 years $^{8}$. It is used to stanch blood, disperse gore, reduce pain, etc. ${ }^{9}$. The pharmacological active substances of $P$. notoginseng are sapoin components, which have been used medicinally for its haemostatic and cardiovascular properties ${ }^{10}$.

The different seed source of $P$. notoginseng samples are very difficult to identify. Accurate evaluate quality of different seed source of $P$. notoginseng samples can facilitate seed selection for the economically field cultivation of $P$. notoginseng. The UV FP compared to HPLC and IR fingerprint had more kindly stability and reproducibility ${ }^{11}$. The vanillin sulphuric acid could improve the similarity of the UV FP of the P. notoginseng ${ }^{12}$. The spectral data were analyzed by the dual-index sequence analytical method, which is an efficient method for classification, identification and discriminate of components of the fingerprint spectra of traditional Chinese medicine ${ }^{13}$.

In this paper, the vanillin sulphuric acid colorimetry-UV FP of the five different seed source of $P$. notoginseng populations were investigated by dual-index sequence analysis of common and variation peak ratio. The aim of this study was to comparative three extract ways of the chemical constituents difference and evaluate quality of different seed of P. notoginseng samples.

\section{EXPERIMENTAL}

UV-2500 UV/visible spectrometer (Shimadzu, Japan), with spectral range: 190-400 nm; DFT-100 type grinder (Zhejiang Wenling City Linda Machinery Co., Ltd., China); SY3200-T type ultrasonic washer (Beijing zhongxi taian technology services company, China); 100 mesh stainless steel sieve (Shanghai shenyuan ultrasonic equipment Co., Ltd., China); AR1140 electronic analytical balance (NJ, USA); UPTI-10 Millipore Waters Milli-Q system (Ulupure, China).

All of $P$. notoginseng samples were three-year age and collected from Xiaoshao field base in Kunming, Yunnan province on October 11, 2012. All of the P. notoginseng samples were authenticated by Dr. Zhang Jin-yu, Institute of Medicinal 
Plants, Yunnan Academy of Agricultural Sciences. Seeds of natural populations of $P$. notoginseng were from five sites of Yanshan County Yunnan Province. Each P. notoginseng sample group's code, number and source of seeds were listed in Table-1.

\begin{tabular}{ccl} 
& \multicolumn{2}{c}{ TABLE-1 } \\
SOURCE OF Panax notoginseng SEED \\
\hline $\begin{array}{c}\text { Sample } \\
\text { group }\end{array}$ & $\begin{array}{c}\text { Number of } \\
\text { samples }\end{array}$ & \multicolumn{1}{c}{$\begin{array}{c}\text { Source of } \\
\text { seeds }\end{array}$} \\
\hline A & 5 & Ban-ge, Yanshan, Yunnan \\
B & 5 & A-meng Yanshan Yunnan \\
C & 5 & Zhe-la Yanshan Yunnan \\
D & 5 & Pan-long Yanshan Yunnan \\
E & 5 & Xiao-shuijing Yanshan Yunnan \\
\hline
\end{tabular}

Ethanol, chloroform, vanillin and sulphuric acid were analytical grades. Double distilled water was obtained from UPT-I-10 Millipore Waters Milli-Q system (Ulupure, China).

Sample processing: Twenty-five different roots of $P$. notoginseng were freeze-dried and grinded to fine powder by grinder. Fifteen hundred $\mathrm{mg}$ of each of the powder of samples was extracted with $20 \mathrm{~mL}$ chloroform and ultrasonication extraction for $20 \mathrm{~min}$. The solid residue powder was isolated and air dried and then extracted with $20 \mathrm{~mL}$ ethanol and ultrasonication extraction for $20 \mathrm{~min}$. The preparation of water extracts were similarly as in ethanol.

Data acquisition: Each $P$. notoginseng sample extracts $5 \mathrm{~mL}$ added with five drops vanillin-sulphuric acid was analyzed by UV-2500. The UV spectra were scanned by UV-2500 at $1 \mathrm{~nm}$ sampling interval and $0.2 \mathrm{~nm}$ slit width between 190 and 400 $\mathrm{nm}$. For UV spectra, the data were treated by the three groups average, the first derivative and the two points smoothing.

Data processing: The data were analyzed by dual-index sequence analysis method. The UV FP of $P$. notoginseng is able to distinguish $P$. notoginseng samples from different seed source. The common and variation peak ratio of UV FP of 25 $P$. notoginseng samples were calculated, respectively. The multiple-dimensional indices were established for distinguishing varieties of $P$. notoginseng samples information. This method was effective to evaluate different $P$. notoginseng samples.

Determination of common and variation peak ratio dual-index of UV FP: Common peak ratio and variation peak ratio were calculated according to the method described by Zou et al. ${ }^{13}$ as follows:

$$
\mathrm{P}=\left(\frac{\mathrm{N}_{\mathrm{g}}}{\mathrm{N}_{\mathrm{d}}}\right) \times 100 \%
$$

$\mathrm{P}$ : common peak ratio, $\mathrm{N}_{\mathrm{g}}$ : The number of common peaks that appeared in both the UV FP compared. $\mathrm{N}_{\mathrm{d}}$ : The total number of peaks that were different in both the UV FP compared.

$$
\mathrm{N}_{\mathrm{d}}=\mathrm{N}_{\mathrm{g}}+\mathrm{n}_{\mathrm{a}}+\mathrm{n}_{\mathrm{b}}
$$

$\mathrm{n}_{\mathrm{a}}$ : The number of variation peaks in UV FP (a), which only belong to UV FP (a). $\mathrm{n}_{\mathrm{b}}$ : The number of variation peaks in UV FP (b), which only belong to UV FP (b).

$$
\mathrm{P}_{\mathrm{va}}=\left(\frac{\mathrm{n}_{\mathrm{A}}}{\mathrm{N}_{\mathrm{g}}}\right) \times 100 \%
$$

$\mathrm{P}_{\mathrm{va}}$ : Variation peak ratio of UV FP (a).

$$
\mathrm{P}_{\mathrm{vb}}=\left(\frac{\mathrm{n}_{\mathrm{b}}}{\mathrm{N}_{\mathrm{g}}}\right) \times 100 \%
$$

$\mathrm{P}_{\mathrm{vb}}$ : Variation peak ratio of UV FP (b).

$$
\begin{aligned}
& \mathrm{N}_{\mathrm{a}}=\mathrm{N}_{\mathrm{g}}+\mathrm{n}_{\mathrm{a}} \\
& \mathrm{N}_{\mathrm{b}}=\mathrm{N}_{\mathrm{g}}+\mathrm{n}_{\mathrm{b}}
\end{aligned}
$$

$\mathrm{N}_{\mathrm{a}}$ : Total number of peaks in UV FP (a). $\mathrm{N}_{\mathrm{b}}$ : The total number of peaks in UV FP (b).

In this method, common and variation peak ratio were used to qualitative evaluate the similarity and difference of more than two samples. The sequence values were arranged according to common peak ratio from high to low, which was called the dual-index sequence of common and variation peak ratio. Each sample stands as a reference. $\mathrm{N}$ samples were constructed by $\mathrm{N}$ sequences and $\mathrm{N}$-dimensional space. Dual-index sequence of common peak ratio and variation peak ratio that could be distinguished one sample at $(2+n)$ dimensional spaces.

\section{RESULTS AND DISCUSSION}

Stability of method: One sample of No. C group was determined at 1, 5, 10, 15, 20, 25 and $30 \mathrm{~h}$. The RSD \% was calculated according to the results of wavelength of peaks in the UV FP of chloroform, ethanol and water extracts of $P$. notoginseng. The RSD \% of three extracts were arranged from $0-0.62,0-0.67$ and $0.07-0.63 \%$, respectively. The analytical results displayed that the three extracts were stable in $30 \mathrm{~h}$.

Precision of method: One sample of No. C group was tested six times. The RSD \% was calculated by wavelength of peaks. The RSD $\%$ of three extracts were arranged from $0-0.63,0-0.57$ and $0-0.76 \%$, respectively. The results showed that this method had a good precision.

Reproducibility of method: One sample of No. C group was accurately weighted six times repeatedly. The RSD \% was calculated by wavelength of peaks. The RSD \% of three extracts were in the range of $0-0.58,0-0.62$ and $0-0.61 \%$, respectively. The results indicated that reproducibility of this method was kindly.

UV FP of the chloroform, ethanol and water extracts: The UV FP of three extracts are shown in Figs. 1-3, respectively. They are very similarity. It showed that the same more of content chemical of $P$. notoginseng extracted by the three solvent, respectively. Because the biological characteristics of Chinese herbal medicines have stability and variability inherited. It indicated the chemical compositions and content of the same producing area and different seed source of $P$. notoginseng are more influenced by environment factors than hereditary.

Dual-index sequence of chloroform extracts: The results of dual-index sequence of the common and variation peak ratio analysis of chloroform extracts are shown in Table-2. From the results, we could find that the maximum common peak ratios of A1:A2, B3:B4, C1:C5, D2:D3 and F3:F4 sequences are $65.85,71.43,73.68,76.92$ and $84.21 \%$, respectively. The minimum common peak ratios of A1:A5, B2:B5, C3:C5, D1:D4 and E4:E5 sequences are 46.67, 48.84, 58.54, 54.55 and $60.47 \%$, respectively. Most of the common peak ratios are more than mean of common peak ratio. For example the sequences of common peak ratio of group A of A1:A2, A2:A4, 


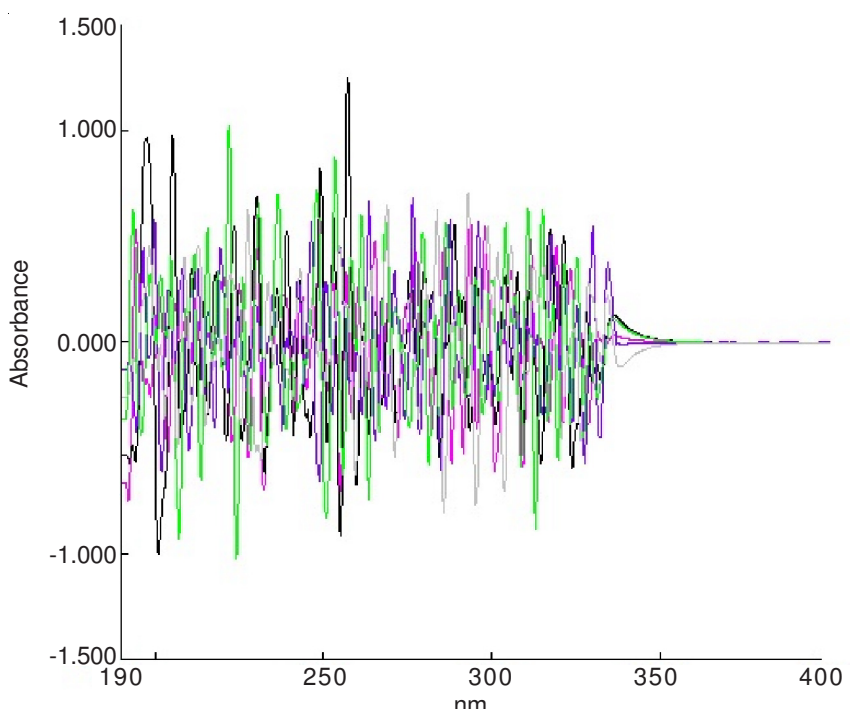

Fig. 1. UV fingerprint of the solution extracted with chloroform

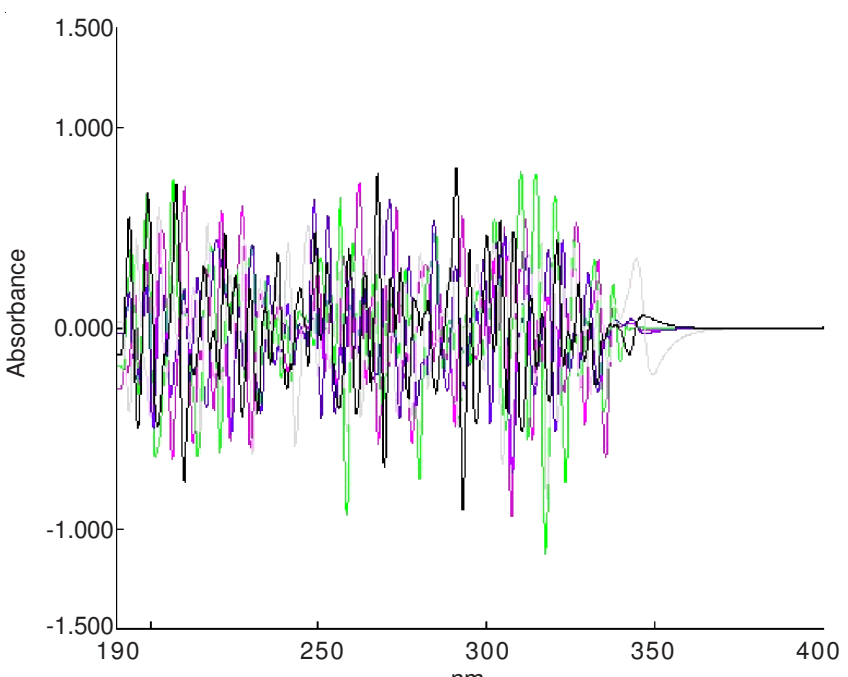

Fig. 2. UV fingerprint of the solution extracted with ethanol

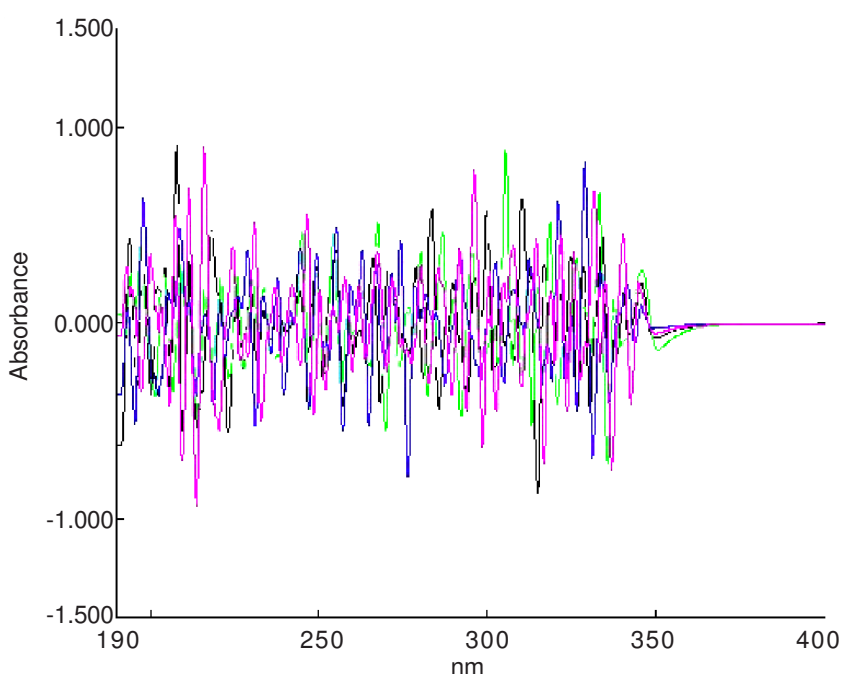

Fig. 3. UV fingerprint of the solution extracted with water

A1:A4 and A2:A3 sequences are over 57.26\%. It indicated that there are substantial similar at the different seed source of $P$. notoginseng samples, because it has stability inherited. This method could identify the different seed source of $P$. notoginseng samples.

\begin{tabular}{|c|c|c|c|}
\hline \multicolumn{4}{|c|}{$\begin{array}{l}\text { TABLE-2 } \\
\text { COMMON AND VARIATION PEAK RATIO IN THE UV } \\
\text { FINGERPRINT REGIONS OF THE CHLOROFORM EXTRACTS }\end{array}$} \\
\hline Sequences & $\mathrm{P}(\%)$ & $\mathrm{P}_{\mathrm{va}}(\%)$ & $\mathrm{P}_{\mathrm{vb}}(\%)$ \\
\hline \multicolumn{4}{|c|}{ Group A } \\
\hline $\mathrm{A} 1: \mathrm{A} 2$ & 65.85 & 25.93 & 25.93 \\
\hline $\mathrm{A} 2: \mathrm{A} 4$ & 65.85 & 25.93 & 25.93 \\
\hline $\mathrm{A} 1: \mathrm{A} 4$ & 61.90 & 30.77 & 30.77 \\
\hline A3:A5 & 60.98 & 36.00 & 28.00 \\
\hline $\mathrm{A} 2: \mathrm{A} 3$ & 58.14 & 36.00 & 36.00 \\
\hline A2:A5 & 57.14 & 41.67 & 33.33 \\
\hline A4:A5 & 57.14 & 41.67 & 33.33 \\
\hline $\mathrm{A} 1: \mathrm{A} 3$ & 51.11 & 47.83 & 47.83 \\
\hline A3:A4 & 47.83 & 54.55 & 54.55 \\
\hline A1:A5 & 46.67 & 61.90 & 52.38 \\
\hline Mean & 57.26 & 40.22 & 36.80 \\
\hline \multicolumn{4}{|c|}{ Group B } \\
\hline B3:B4 & 71.43 & 23.33 & 16.67 \\
\hline $\mathrm{B} 2: \mathrm{B} 3$ & 64.29 & 18.52 & 37.04 \\
\hline B3:B5 & 64.29 & 37.04 & 18.52 \\
\hline $\mathrm{B} 1: \mathrm{B} 5$ & 61.90 & 38.46 & 23.08 \\
\hline $\mathrm{B} 2: \mathrm{B} 4$ & 59.52 & 28.00 & 40.00 \\
\hline B4:B5 & 59.52 & 40.00 & 28.00 \\
\hline B1:B3 & 58.70 & 33.33 & 37.04 \\
\hline B1:B4 & 57.78 & 38.46 & 34.62 \\
\hline $\mathrm{B} 1: \mathrm{B} 2$ & 54.55 & 50.00 & 33.33 \\
\hline $\mathrm{B} 2: \mathrm{B} 5$ & 48.84 & 52.38 & 52.38 \\
\hline Mean & 60.08 & 35.95 & 32.07 \\
\hline \multicolumn{4}{|c|}{ Group C } \\
\hline $\mathrm{C} 1: \mathrm{C} 5$ & 73.68 & 21.43 & 14.29 \\
\hline $\mathrm{C} 1: \mathrm{C} 2$ & 70.00 & 21.43 & 21.43 \\
\hline $\mathrm{C} 2: \mathrm{C} 4$ & 66.67 & 21.43 & 28.57 \\
\hline $\mathrm{C} 3: \mathrm{C} 4$ & 64.29 & 22.22 & 33.33 \\
\hline $\mathrm{C} 2: \mathrm{C} 3$ & 63.41 & 30.77 & 26.92 \\
\hline $\mathrm{C} 1: \mathrm{C} 4$ & 62.79 & 25.93 & 33.33 \\
\hline $\mathrm{C} 4: \mathrm{C} 5$ & 61.90 & 38.46 & 23.08 \\
\hline $\mathrm{C} 2: \mathrm{C} 5$ & 60.98 & 36.00 & 28.00 \\
\hline $\mathrm{C} 1: \mathrm{C} 3$ & 59.52 & 36.00 & 32.00 \\
\hline $\mathrm{C} 3: \mathrm{C} 5$ & 58.54 & 37.50 & 33.33 \\
\hline Mean & 64.18 & 29.12 & 27.43 \\
\hline \multicolumn{4}{|c|}{ Group D } \\
\hline D2:D3 & 76.92 & 16.67 & 13.33 \\
\hline D2:D4 & 72.50 & 20.69 & 17.24 \\
\hline D3:D4 & 70.00 & 21.43 & 21.43 \\
\hline D2:D5 & 60.98 & 40.00 & 24.00 \\
\hline D1:D2 & 60.47 & 30.77 & 34.62 \\
\hline D4:D5 & 58.54 & 41.67 & 29.17 \\
\hline D1:D5 & 54.76 & 47.83 & 34.78 \\
\hline D3:D5 & 54.76 & 47.83 & 34.78 \\
\hline D1:D3 & 54.55 & 41.67 & 41.67 \\
\hline D1:D4 & 54.55 & 41.67 & 41.67 \\
\hline Mean & 61.80 & 35.02 & 29.27 \\
\hline \multicolumn{4}{|c|}{ Group E } \\
\hline E3:E4 & 84.21 & 9.38 & 9.38 \\
\hline E2:E3 & 80.00 & 15.63 & 9.38 \\
\hline $\mathrm{E} 2: \mathrm{E} 4$ & 80.00 & 15.63 & 9.38 \\
\hline E1:E5 & 69.23 & 18.52 & 25.93 \\
\hline E2:E5 & 69.05 & 27.59 & 17.24 \\
\hline E1:E4 & 67.50 & 18.52 & 29.63 \\
\hline E1:E2 & 64.29 & 18.52 & 37.04 \\
\hline E3:E5 & 64.29 & 29.63 & 25.93 \\
\hline E1:E3 & 63.41 & 23.08 & 34.62 \\
\hline E4:E5 & 60.47 & 34.62 & 30.77 \\
\hline Mean & 70.24 & 21.11 & 22.93 \\
\hline
\end{tabular}


TABLE-3

COMMON AND VARIATION PEAK RATIO IN THE UV FINGERPRINT REGIONS OF GROUP A EXTRACTED BY CHLOROFORM, ETHANOL AND WATER

\begin{tabular}{|c|c|c|c|}
\hline Sequences & $\mathrm{P}(\%)$ & $\mathrm{P}_{\mathrm{va}}(\%)$ & $\mathrm{P}_{\mathrm{vb}}(\%)$ \\
\hline \multicolumn{4}{|c|}{ Chloroform } \\
\hline A1:A2 & 65.85 & 25.93 & 25.93 \\
\hline $\mathrm{A} 2: \mathrm{A} 4$ & 65.85 & 25.93 & 25.93 \\
\hline A1:A4 & 61.90 & 30.77 & 30.77 \\
\hline A3:A5 & 60.98 & 36.00 & 28.00 \\
\hline $\mathrm{A} 2: \mathrm{A} 3$ & 58.14 & 36.00 & 36.00 \\
\hline A2:A5 & 57.14 & 41.67 & 33.33 \\
\hline $\mathrm{A} 4: \mathrm{A} 5$ & 57.14 & 41.67 & 33.33 \\
\hline $\mathrm{A} 1: \mathrm{A} 3$ & 51.11 & 47.83 & 47.83 \\
\hline $\mathrm{A} 3: \mathrm{A} 4$ & 47.83 & 54.55 & 54.55 \\
\hline A1:A5 & 46.67 & 61.90 & 52.38 \\
\hline Mean & 57.26 & 40.22 & 36.80 \\
\hline \multicolumn{4}{|c|}{ Ethanol } \\
\hline $\mathrm{A} 1: \mathrm{A} 2$ & 68.18 & 40.00 & 6.67 \\
\hline A1:A5 & 66.67 & 40.00 & 10.00 \\
\hline A1:A3 & 65.96 & 35.48 & 16.13 \\
\hline $\mathrm{A} 1: \mathrm{A} 4$ & 65.22 & 40.00 & 13.33 \\
\hline A3:A5 & 60.47 & 38.46 & 26.92 \\
\hline A3:A4 & 59.09 & 38.46 & 30.77 \\
\hline $\mathrm{A} 2: \mathrm{A} 3$ & 54.55 & 33.33 & 50.00 \\
\hline $\mathrm{A} 4: \mathrm{A} 5$ & 52.27 & 47.83 & 43.48 \\
\hline A2:A5 & 51.16 & 45.45 & 50.00 \\
\hline $\mathrm{A} 2: \mathrm{A} 4$ & 40.43 & 68.42 & 78.95 \\
\hline Mean & 58.40 & 42.74 & 32.62 \\
\hline \multicolumn{4}{|c|}{ Water } \\
\hline A4:A5 & 71.43 & 16.67 & 23.33 \\
\hline $\mathrm{A} 1: \mathrm{A} 4$ & 71.43 & 23.33 & 16.67 \\
\hline $\mathrm{A} 1: \mathrm{A} 5$ & 70.83 & 20.59 & 20.59 \\
\hline $\mathrm{A} 3: \mathrm{A} 5$ & 69.77 & 20.00 & 23.33 \\
\hline $\mathrm{A} 1: \mathrm{A} 3$ & 69.77 & 23.33 & 20.00 \\
\hline $\mathrm{A} 2: \mathrm{A} 3$ & 68.29 & 17.86 & 28.57 \\
\hline A3:A4 & 65.12 & 28.57 & 25.00 \\
\hline $\mathrm{A} 1: \mathrm{A} 2$ & 60.47 & 42.31 & 23.08 \\
\hline $\mathrm{A} 2: \mathrm{A} 5$ & 59.09 & 26.92 & 42.31 \\
\hline A2:A4 & 54.55 & 37.50 & 45.83 \\
\hline Mean & 66.07 & 25.71 & 26.87 \\
\hline
\end{tabular}

Dual-index sequence of the group A sample: From the Table-3, the sequences of the common peak ratio of the samples are generally similar and the relationships among samples are closest. They are in range from $40-70 \%$. The maximum common peak ratios of chloroform, ethanol and water extracts are 65.85 , 68.18 and $71.43 \%$, respectively. The minimum common peak ratios of the three extractions are 46.67, 40.43 and $54.55 \%$, respectively. It indicated that they are substantial similar among the same ages and producing areas of $P$. notoginseng samples. The mean value common peak ratios of the three extractions are $57.26,58.40$ and $66.07 \%$, respectively. It indicated that the three extractions could provide the effective information of resource identification. Zhang et al ${ }^{14}$ applied the common and variation peak ratio dual index sequence analysis method studied chloroform, ethanol and water extracts of the same producing areas of Paris. The results showed this method could clarify the similarity between the species and areas of Paris. The maximum variation peak ratios of the three extractions are $61.9,45.83$ and $78.95 \%$, respectively. The minimum variation peak ratios of them are $25.93,16.67$ and $6.67 \%$, respectively. It showed that there are different chemical constituents among same producing areas and age of $P$. notoginseng. The results tell us that three extractions could be used effective to identify the herbal samples $P$. notoginseng.

\section{Conclusion}

The vanillin sulduric acid colorimetry-UV FP of $P$. notoginseng could be used exactly in qualitative evaluation of $P$. notoginseng samples. This study can be used to evaluate accurately the qualities among different seed source of $P$. notoginseng samples by the common and variation peak ratio dual index sequence analysis method. The experimental results showed that there is a good correlation between UV FP and P. notoginseng samples of quality and there are significant of quality of five different seed source of $P$. notoginseng populations of the vanillin sulphuric acid colorimetry-UV FP, then the three extractions of the different chemical constitents of the different seed source of $P$. notoginseng could be identified accurately and quickly. This method could also be applied the basement for identification and quality evaluation of herbs.

\section{ACKNOWLEDGEMENTS}

This work was supported by the National Natural Science Foundation of China (81260610; 81260608), National Key Technology R\&D Program of China (2011BAI13B01-02; 2011BAI13BO2-04) and Special Research Foundation of Ministry of Agriculture in the Public Interest (201303117; 201303138).

\section{REFERENCES}

1. D.L. Luthria, S. Mukhopadhyay, R.J. Robbins, J.W. Finley, G.S. Banuelos and J.M. Harnly, J. Agric. Food Chem., 56, 5457 (2008).

2. M.A. Farag, A. Porzel and L.A. Wessjohann, Phytochemistry, 76, 60 (2012).

3. YY.S. Shin, K.H. Bang, D.S. In, O.T. Kim, D.Y. Hyun, I.O. Ahn, B.C. Ku, S.W. Kim, N.S. Seong, S.W. Cha, D. Lee and H.K. Choi, Arch. Pharm. Res., 30, 1625 (2007).

4. C. Sârbu, R.D. Nascu-briciu, A. Kot-wasik, S. Gorinstein, A. Wasik and J. Namiesnik, Food Chem., 130, 994 (2012).

5. M.Q. Shan, X.D. Yao, Y.M. Chi, L. Zhang and A.W. Ding, Spectrosc. Spectr. Anal., 29, 2092 (2009).

6. M. Insausti, A.A. Gomes, F.V. Cruz, M.F. Pistonesi, M.C.U. Araujo, R.K.H. Galvão, C.F. Pereira and B.S.F. Band, Talanta, 97, 579 (2012).

7. T.J. Yuan, Y.Z. Wang, Y.L. Zhao, J. Zhang, H. Jin and J.Y. Zhang, Spectrosc. Spectr. Anal., 31, 2161 (2011).

8. H.B. Guo, X.M. Cui, N. An and G.P. Cai, Genet. Resour. Crop Evol., 57, 453 (2010).

9. Chinese Pharmacopoeia of the People's Republic of China (Part One), China Pharmacopoeia Commission, China Medical Science Press, Beijing, p. 11 (2010).

10. D. Wang, P.Y. Liao, H.T. Zhu, K.K. Chen, M. Xu, Y.J. Zhang and C.R. Yang, Food Chem., 132, 1808 (2012).

11. H.B. Zou, J.R. Yuan, A.Q. Du, L.L. Sun and H.Y. Aboul-Enein, Anal. Lett., 38, 1167 (2005).

12. Y.L. Ding, Y.Z. Wang, J. Zhang, Q.Z. Zhang, J.Y. Zhang and H. Jin, Spectrosc. Spectr. Anal., 33, 471 (2013).

13. H.B. Zou, G.S. Yang, Z.R. Qin, W.-Q. Jiang, A.-Q. Du and H.Y. AboulEnein, Anal. Lett., 38, 1457 (2005).

14. J.Y. Zhang, Y.Z. Wang, Y.L. Zhao, J. Zhang, T.J. Yuan, J.J. Wang and H. Jin, Spectrosc. Spectr. Anal., 32, 2176 (2012). 